\title{
Urolithiasis in Italy: An epidemiological study
}

\author{
Domenico Prezioso $^{1}$, Ester Illiano ${ }^{1}$, Gaetano Piccinocchi ${ }^{2}$, Claudio Cricelli $^{2}$, Roberto Piccinocchi ${ }^{3}$, \\ Alberto Saita ${ }^{4}$, Carla Micheli ${ }^{5}$, Alberto Trinchieri ${ }^{6}$ \\ ${ }^{1}$ Department of Neuroscience, Reproductive Sciences and Dentistry, University Federico II of Naples, Naples, Italy; \\ 2 SIMG, Italian Society of General Medicine; \\ ${ }^{3}$ University "Campus Biomedico" of Rome, Rome, Italy; \\ ${ }^{4}$ Department of Urology, "Vittorio Emanuele Hospital", University of Catania, Catania, Italy; \\ ${ }^{5}$ Department of Urology and Andrology, Santa Maria della Misericordia Hospital, University of Perugia, Perugia, Italy; \\ ${ }^{6}$ Department of Urology Alessandro Manzoni Hospital of Lecco, Lecco, Italy.
}

\begin{abstract}
Summary Objectives: Worldwide the urolithiasis is the third most frequent urological disease affecting both males and females. In literature there are not recent Italian epidemiological data about stone disease. The objective of this study is the evaluation of current epidemiology of urolithiasis in Italy using the Health Search/CSD Longitudinal Patient Database (HS) database. Material and methods: An observational, descriptive, retrospective trial was conducted. Inclusion criteria were: family physician- assisted Italian living population member of HS database within 31 December 2012, both genders, age over 17 years, at least two years of clinical history recorded from the beginning the trial. Data were collected by HS database and elaborated by its software Millewin ${ }^{\circledR}$. Results: In Italy prevalence of urolithiasis in 2012 was $4.14 \%$, it was higher in males than in females $(4.53 \%$ versus $3.78 \%$ ) with a positive relation with increasing age. The highest prevalence rate of urolithiasis was reported in the region Campania (6.08\%). The general incidence was $2.23 * 1000$, with the highest incidence in the region Sicilia $(3.15 * 1000)$. Incidence was higher in group age 65-74 years $(3.18 * 1000)$.

Conclusions: In Italy the incidence and prevalence of urolithiasis is increasing with particular distribution in relation to gender, age and regional position.
\end{abstract}

KEY WORDS: Urolithiasis, prevalence; Incidence; Epidemiological trial.

Submitted 26 January 2014; Accepted 31 March 2014

\section{INTRODUCTION}

Urolithiasis is a major clinical and economic burden for healthcare systems; infact is a highly prevalent condition with a high recurrence rate that has a large impact on the quality of life of those affected (1). In 1994 in Italy the National Institute of Statistics (ISTAT) database showed the prevalence as $1.7 \%$ and the incidence as 0.17 case/1000 patient with 95000 new cases/year. A national study of family physicians of the Società Italiana di Medicina Generale (SIMG) in 2006 showed that 19\% patients with urolithiasis undergo urologic visit, $4.6 \%$ hospitalization, $48.8 \%$ ultra- sonography (US), 7.2\% urography, 2.6\% non-contrast enhanced computed tomography (NCCT), 3.4\% kidneyureter-bladder radiography (KUB) (2). International epidemiological data suggest that the incidence and prevalence of stone disease is increasing (3-11) and an increase is recorded mainly in industrialized countries, as well in western countries probably resulting from improvements in clinical-diagnostic procedures and changes in nutritional and environmental factors (12). Many population-based studies investigated prevalence and incidence rates of urolithiasis in different countries. Nevertheless it is important to emphasize that precise data on the epidemiology of a disease or disorder can only be determined if geographical position, race, age and sex, climate, nutrition and other environmental factors are also taken in consideration. When analysing the literature, we can highlight the scarcity of new Italian epidemiological data about stone disease. These epidemiological data are very important in the planning of health services and social-health; in clinical governance and in assessing the quality of services performed and their impact in terms of both clinical benefits as well as financial savings. To achieve these goals is needed to draw the real dimension of problem, especially the epidemiological dimension. In the latter part of the $20^{\text {th }}$ century and in the early of $21^{\text {th }}$ century a growing application of epidemiological methods was observed, with well-structured analysis of prescriptive profile and flow chart. In Italy this system was combined with an evolution in the management of health informatics systems from the collection and storage of performance data and the related reimbursement by the regional health system (eg. hospitalizations, outpatient specialist care, pharmaceutical prescriptions). These are business systems, however are used as economic, clinical and epidemiological database also. This study seeks to evaluate current Italian epidemiological situation about stone disease using Health Search/CSD Longitudinal Patient Database (HS) database used by SIMG.

\section{Material AND METHOdS}

The study was designed as a observational, descriptive, retrospective trial. The objective is the evaluation of total

No conflict of interest declared. 
prevalence and incidence of urolithiasis in Italian population in 2012 divided by region, age and gender. Inclusion criteria were: family physician- assisted Italian living population members included in HS database within 31 December 2012 of both genders, aged over 17 years, with at least two years of clinical history recorded from the beginning the trial. The physicians participating to the study were 650 and were considered the most reliable among 1000 family physicians using HS. In fact in 19981000 Italian familyphysicians were involved in a project of electronic medical recording (EMR) in order to create a large HS database. In 2009, 650 Italian family-physicians out of the total 1000 Italian family-physician initially involved were selected according to their geographical distribution (Northeast, Northwest, Central, South, Islands). This group of "selected" 650 family physicians is composed by family physicians who ensured the best quality of reporting in epidemiological research. In order to select this group a quality score was calculated for each family physician. The geographical distribution of patients of these family physicians is similar to general Italian population census by ISTAT, without significant differences both in geographical location and age distribution. Registered informations were: demographic informations and clinical informations such as Body Mass Index (BMI), smoking, pressure blood value, biochemistry data, imaging, hospitalization, drugs etc. Each patient was labelled with a nameless code, so all informations of each patient were reported with equivalent code. The nomenclature of was concordant with Official Journal, drug's names were concordant with coding of Anatomical Therapeutic Chemical Classification System (ATC) and diseases were concordant with coding of International Classification of Diseases $9^{\circ}$ Edition (ICD-9). Data were collected by the database Health Search and elaborated by its software Millewin ${ }^{\circledR}$.

\section{RESULTS}

The examined population is 900.994 with a regional allocation showed in Table 1. This table shows the numbers (and rates) of family physician-assisted Italian living population members included in HS database within 31
Table 1.

Family physician-assisted Italian living population member of database HS within 31 December 2012 by Italian region and gender.

\begin{tabular}{|l|cc|cc|cc}
\hline \multirow{2}{*}{ Region } & \multicolumn{2}{|c|}{ Total } & \multicolumn{2}{c|}{ Male } & \multicolumn{2}{c}{ Female } \\
\hline Piemonte/Aosta & 61701 & 6.85 & 29756 & 6.87 & 31945 & 6.82 \\
\hline Liguria & 29791 & 3.31 & 14081 & 3.25 & 15710 & 3.36 \\
\hline Lombardia & 140973 & 15.65 & 69138 & 15.97 & 71835 & 15.34 \\
\hline Trentino/FVG & 46451 & 5.16 & 22196 & 5.13 & 24255 & 5.18 \\
\hline Veneto & 72553 & 8.05 & 35135 & 8.12 & 37418 & 7.99 \\
\hline Emilia Romagna & 54403 & 6.04 & 25421 & 5.87 & 28982 & 6.19 \\
\hline Toscana & 46800 & 5.19 & 22555 & 5.21 & 24245 & 5.18 \\
\hline Umbria & 25127 & 2.79 & 11996 & 2.77 & 13131 & 2.80 \\
\hline Marche & 24930 & 2.77 & 12249 & 2.83 & 12681 & 2.71 \\
\hline Lazio & 79945 & 8.87 & 37788 & 8.73 & 42157 & 9.00 \\
\hline Abruzzo/Molise & 29723 & 3.30 & 14035 & 3.24 & 15688 & 3.35 \\
\hline Campania & 77616 & 8.61 & 37134 & 8.58 & 40482 & 8.65 \\
\hline Puglia & 65505 & 7.27 & 31682 & 7.32 & 33823 & 7.22 \\
\hline Basilicata/Calabria & 41207 & 4.57 & 20052 & 4.63 & 21155 & 4.52 \\
\hline Sicilia & 81595 & 9.06 & 38830 & 8.97 & 42765 & 9.13 \\
\hline Sardegna & 22666 & 2.52 & 10765 & 2.49 & 11901 & 2.54 \\
\hline Total & 900.994 & 100.00 & 432816 & 100.00 & 468178 & 100.00 \\
\hline
\end{tabular}

FFVG: Friuli Venezia Giulia. HS: Health Search/CSD Longitudinal Patient Database. N: Number.

Table 2.

Family physician-assisted Italian living population member of database HS within 31 December 2012 by class age and gender.

\begin{tabular}{|l|cc|cc|cc|}
\hline & \multicolumn{2}{|c|}{ Total } & \multicolumn{2}{c|}{ Male } & \multicolumn{2}{c|}{ Female } \\
\hline Age & $\mathbf{N}$ & $\%$ & $\mathbf{N}$ & $\%$ & $\mathbf{N}$ & $\%$ \\
\hline $15-24$ & 92113 & 10.22 & 47883 & 11.06 & 44230 & 9.45 \\
\hline $25-34$ & 121663 & 13.50 & 60975 & 14.09 & 60688 & 12.96 \\
\hline $35-44$ & 160896 & 17.86 & 79737 & 18.42 & 81159 & 17.34 \\
\hline $45-54$ & 163813 & 18.18 & 80216 & 18.53 & 83597 & 17.86 \\
\hline $55-64$ & 135266 & 15.01 & 66156 & 15.29 & 69110 & 14.76 \\
\hline $65-74$ & 114032 & 12.66 & 54314 & 12.55 & 59718 & 12.76 \\
\hline $75-84$ & 80967 & 8.99 & 33309 & 7.70 & 47658 & 10.18 \\
\hline$\geq 85$ & 32244 & 3.58 & 10226 & 2.36 & 22018 & 4.70 \\
\hline HS: Health Search/CSD Longitudinal Patient Database. N: Number. \\
\hline
\end{tabular}

Table 3.

Prevalence of urolithiasis in family physician-assisted Italian living population member of database HS within 31 December 2012 by Italian region and gender.

\begin{tabular}{|l|cc|cc|cc|}
\hline \multirow{2}{*}{ Region } & \multicolumn{2}{|c|}{ Total } & \multicolumn{2}{c|}{ Male } & \multicolumn{2}{c|}{ Female } \\
\hline Piemonte/Aosta & 2237 & 3.63 & 1241 & 4.17 & 996 & 3.12 \\
\hline Liguria & 1104 & 3.71 & 634 & 4.50 & 470 & 2.99 \\
\hline Lombardia & 4413 & 3.13 & 2547 & 3.68 & 1866 & 2.60 \\
\hline Trentino/FVG & 1216 & 2.62 & 699 & 3.15 & 517 & 2.13 \\
\hline Veneto & 2119 & 2.92 & 1222 & 3.48 & 897 & 2.40 \\
\hline Emilia Romagna & 2486 & 4.57 & 1436 & 5.65 & 1050 & 3.62 \\
\hline Toscana & 1756 & 3.75 & 1063 & 4.71 & 693 & 2.86 \\
\hline Umbria & 960 & 3.82 & 592 & 4.94 & 368 & 2.80 \\
\hline Marche & 1334 & 5.35 & 770 & 6.29 & 564 & 4.45 \\
\hline Lazio & 3160 & 3.95 & 1635 & 4.33 & 1525 & 3.62 \\
\hline Abruzzo/Molise & 1306 & 4.39 & 659 & 4.70 & 647 & 4.12 \\
\hline Campania & 4718 & 6.08 & 2105 & 5.67 & 2613 & 6.46 \\
\hline Puglia & 3072 & 4.69 & 1461 & 4.61 & 1611 & 4.76 \\
\hline Basilicata/Calabria & 2107 & 5.11 & 977 & 4.87 & 1130 & 5.34 \\
\hline Sicilia & 4355 & 5.34 & 2135 & 5.50 & 2220 & 5.19 \\
\hline Sardegna & 966 & 4.26 & 446 & 4.14 & 520 & 4.37 \\
\hline Total & 37316 & 4.14 & 19626 & 4.53 & 17690 & 3.78 \\
\hline FFVG: Friuli Venezia Giulia. HS: Health Search/CSD Longitudinal Patient Database. N: Number. & \\
\hline
\end{tabular}


Table 4.

Prevalence of urolithiasis in family physician-assisted Italian living population member of database HS within 31 December 2012 by age and gender.

\begin{tabular}{|l|cc|cc|cc}
\hline \multirow{2}{*}{ Age } & \multicolumn{2}{|c|}{ Total } & \multicolumn{2}{c|}{ Male } & \multicolumn{2}{c}{ Female } \\
\hline $15-24$ & 601 & 0.65 & 236 & 0.49 & 365 & 0.83 \\
\hline $25-34$ & 2303 & 1.89 & 928 & 1.52 & 1375 & 2.27 \\
\hline $35-44$ & 4903 & 3.05 & 2384 & 2.99 & 2519 & 3.10 \\
\hline $45-54$ & 7381 & 4.51 & 3941 & 4.91 & 3440 & 4.12 \\
\hline $55-64$ & 8012 & 5.92 & 4562 & 6.90 & 3450 & 4.99 \\
\hline $65-74$ & 7646 & 6.71 & 4355 & 8.02 & 3291 & 5.51 \\
\hline $75-84$ & 5142 & 6.35 & 2633 & 7.91 & 2509 & 5.27 \\
\hline$\geq 85$ & 1328 & 4.12 & 587 & 5.74 & 741 & 3.37 \\
\hline
\end{tabular}

HS: Health Search/CSD Longitudinal Patient Database. N: Number.

Table 5.

Incidence of urolithiasis in family physician-assisted Italian living population member of database HS within 31 December 2012 by Italian region and gender.

\begin{tabular}{|c|c|c|c|c|c|c|}
\hline \multirow[b]{2}{*}{ Region } & \multicolumn{2}{|c|}{ Total } & \multicolumn{2}{|c|}{ Male } & \multicolumn{2}{|c|}{ Female } \\
\hline & $\mathbf{N}$ & *1000 & $\mathbf{N}$ & *1000 & $\mathbf{N}$ & *1000 \\
\hline Piemonte/Aosta & 106 & 1.71 & 61 & 2.05 & 45 & 1.39 \\
\hline Liguria & 77 & 2.54 & 36 & 2.52 & 41 & 2.55 \\
\hline Lombardia & 296 & 2.05 & 163 & 2.31 & 133 & 1.80 \\
\hline Trentino/FVG & 53 & 1.10 & 29 & 1.27 & 24 & 0.95 \\
\hline Veneto & 105 & 1.40 & 57 & 1.58 & 48 & 1.23 \\
\hline Emilia Romagna & 153 & 2.72 & 90 & 3.43 & 63 & 2.10 \\
\hline Toscana & 78 & 1.44 & 45 & 1.73 & 33 & 1.17 \\
\hline Umbria & 45 & 1.77 & 32 & 2.66 & 13 & 0.97 \\
\hline Marche & 51 & 2.02 & 33 & 2.67 & 18 & 1.40 \\
\hline Lazio & 230 & 2.72 & 107 & 2.71 & 123 & 2.73 \\
\hline Abruzzo/Molise & 63 & 1.97 & 30 & 2.00 & 33 & 1.95 \\
\hline Campania & 218 & 2.71 & 114 & 2.97 & 104 & 2.47 \\
\hline Puglia & 174 & 2.53 & 78 & 2.36 & 96 & 2.70 \\
\hline Basilicata/Calabria & 113 & 2.66 & 64 & 3.10 & 49 & 2.24 \\
\hline Sicilia & 260 & 3.15 & 108 & 2.76 & 152 & 3.49 \\
\hline Sardegna & 61 & 2.52 & 30 & 2.61 & 31 & 2.44 \\
\hline Total & 2090 & 2.23 & 1082 & 2.42 & 1008 & 2.06 \\
\hline
\end{tabular}

FFVG: Friuli Venezia Giulia. HS: Health Search/CSD Longitudinal Patient Database. N: Number.

Table 6.

Incidence of urolithiasis in family physician-assisted Italian living population member of database HS within 31 December 2012 by age and gender.

\begin{tabular}{|l|cc|cc|cc}
\hline Age & \multicolumn{2}{|c|}{ Total } & \multicolumn{2}{c|}{ Male } & \multicolumn{2}{c}{ Female } \\
\hline $15-24$ & $\mathbf{N}$ & ${ }^{*} \mathbf{1 0 0 0}$ & $\mathbf{N}$ & ${ }^{*} \mathbf{1 0 0 0}$ & $\mathbf{N}$ & ${ }^{*} \mathbf{1 0 0 0}$ \\
\hline $25-34$ & 81 & 0.95 & 34 & 0.77 & 47 & 1.15 \\
\hline $35-44$ & 184 & 1.49 & 89 & 1.44 & 95 & 1.54 \\
\hline $45-54$ & 309 & 1.86 & 179 & 2.18 & 130 & 1.54 \\
\hline $55-64$ & 438 & 2.56 & 226 & 2.70 & 212 & 2.42 \\
\hline $65-74$ & 447 & 3.12 & 246 & 3.53 & 201 & 2.74 \\
\hline $75-84$ & 388 & 3.18 & 193 & 3.34 & 195 & 3.03 \\
\hline$\geq 85$ & 211 & 2.40 & 100 & 2.75 & 111 & 2.15 \\
\hline
\end{tabular}

HS: Health Search/CSD Longitudinal Patient Database. N: Number.

December 2012 divided by Italian region and gender (432.816 male versus 468.178 female) while Table 2 shows the same population divided by class age $(64.55 \% 25-64$ years, while $12.57 \% \geq 75$ years) and gender $(66.33 \% 25$ 64 years males versus 62.92\% 25-64 years females). Patients members of HS database within 31 December 2012 with urolithiasis were $37.316,4.14 \%$ of total family physician-assisted Italian living population members of HS database within 31 December 2012 (Table 3). This table shows an higher prevalence in males compared to females (M $4.53 \%$ versus $\mathrm{F}$ $3.78 \%$ ) also, while table 4 shows a positive relation with increasing age. The highest prevalence (6.08\%) of urolithiasis was observed in Campania (Table 3), followed by Marche $5.35 \%$ and Sicilia $5.34 \%$ whereas the lowest was recorded in Trentino/Friuli Venezia Giulia 3.15\% (Table 3). In almost all the Italian regions the prevalence of stone disease is higher in males (Table 3), but in some regions such as Campania (M 5.67\% vs F 6.46\%), Puglia (M 4.61\% vs F 4.76\%), Basilicata/Calabria (M $4.87 \%$ vs $\mathrm{F}$ $5.34 \%$ ), and Sardegna (M $4.14 \%$ vs F $4.37 \%$ ) the prevalence is higher in females (Table 3). The higher prevalence was observed in 65-74 years class age (Table 4), rating $6.71 \%$ (M $8.02 \%$ and $\mathrm{F} 5.51 \%$ ), followed by the $75-84$ years $(6.35 \%)$ and $55-64$ years (5.92\%) age groups (Table 4). Incidence of urolithiasis in family physician-assisted Italian living population member of HS database within 31 December 2012 was $2.23 * 1000$, with the highest rate in Sicilia (3.15*1000) (Table 5). In Emilia Romagna an higher incidence was recorded among males $(3.43 * 1000)$, while in Sicilia among females (3.49 *1000) (Table 5). As well as the prevalence, the incidence was higher in 65-74 years group age $(3.18 * 1000)$ (Table 6). Female are more affected in this group age $(3.03 * 1000)$, while male in 55-64 years group age $(3.53 * 1000)$ (Table 6$)$.

\section{Discussion}

When comparing the epidemiological data of this study with those from literature, temporal references should be taken into account In fact population members of HS database were included within 31 December 2012, whereas those in the literature are related to previous periods, and this condition may have influence on the epidemiology of this chronic disease whose prevalence and incidence trends in recent decades have been changing. The lifetime prevalence of kidney stone disease is estimated at $1 \%$ to $15 \%$, with the probability of having a stone varying according to age, gender, race, and geographic location. In previous reports the prevalence of kidney stones varied greatly between geographic locations, ranging from $8 \%$ to 19\% in males and from 3\% to 5\% in females in Western countries (12). It has been apparent for several years that the inci- 
dence rates of lithiasis vary dramatically, not only from continent to continent, but also between adjacent regions of a country, even if one allows for differences in methodology and criteria selection among epidemiology studies $(13,14)$ Infact epidemiological data on the occurrence of urolithiasis ranges between $2 \%$ and $20 \%$ worldwide $(15,16)$ (being most common in South and South Eastern regions of United States, as well as in Central Europe and the Mediterranean area, India and Northern Pakistan, Northern Australia and China) (17) In our study the prevalence in 2012 in Italy is $4.14 \%$, while the incidence is $2.23 * 1000$, with a geographic distribution showing higher prevalences and incidences in Southern regions. This can be easily explained, by the well documented knowledge that the incidence of urinary stones is higher in countries with warm or hot climates, probably due to low urinary output and scant fluid intake (18). Seasonal variation in stone disease is likely related to temperature by way of fluid losses through perspiration and perhaps by sunlight -induced increases in vitamin D (19). In a previous study of the SIMG (2) in 2008, the prevalence of urolithiasis in Italy was evaluated at a lower rate of $3.1 \%$. The higher rate demonstrated in the present study confirm in our country the increasing trend reported in the rest of the world. Stone disease typically affects adult men more commonly than adult woman (12). Howerver Scales et al. (20) observed a dramatic increase from 1997 to 2002 of the adjusted rate of discharges for stone disease in females in American population with a change from 1.7:1 to 1.3:1 of the male-tofemale ratio. The increasing incidence of nephrolithiasis in women might be due to lifestyle associated risk factors, such as obesity (20). In Italy the rates in 2012 confirm the 2008 data (2) with higher prevalence in males than in females (M 3.4 vs. F 2.8\%) but contrasting results were observed in southern regions.. Data from the American database National Health and Nutrition Examination Survey (NHANES) indicate that stone prevalence increased in all age groups from 1980 to 1994 though, despite more than 15,000 participants at each time point, the increase was statistically significant only for men aged 60-74 (21).

In Italy hypercalciuria was more frequent in patients aged $20-39$ years $(50.3 \%)$ than in older patients $(36 \%)$ and hyperuricosuria was lower in the younger patients (5\%) than in the older patients (10\%) (22). In our study the age group most affected is $65-74$ years $(6.71 \%, \mathrm{M} 8.02 \%$ and F $5.51 \%$ ), instead of the 55-64 years age group (4.5\% M 5.40\% and F 3.60\%) in 2008 (2), however in both studies a similar trend was observed.

\section{Conclusions}

This is the first study that evaluated prevalence and incidence of urolithiasis in Italy by age, gender and Italian region. These data are important for clinical workforce planning, training, service delivery and research in the field of urolithiasis.

\section{REFEREnCES}

1. Semins MJ. Medical evaluation and management of urolithiasis. Ther Adv Urol. 2010; 2:3-9.

2. Campo S, Pasqua A, Simonetti M, Mazzaglia G. Studio sulla nefrolitiasi nel setting delle cure primarie italiane. Rivista della Società Italiana di Medicina Generale 2011; 2:1-5.
3. Pearle M, Calhoun E, Curhan G. Urologic diseases in America project: urolithiasis J Urol. 2005; 173:848-57.

4. Romero V, Akpinar H, Assimos D. Kidney stones: a global picture of prevalence, incidence, and associated risk factors. Rev Urol. 2010; 12:86-96.

5. Stamatelou K, Francis M, Jones C, et al. Time trends in reported prevalence of kidney stones in the United States: 1976-1994. Kidney Int. 2003; 63:1817-23.

6. Soucie J, Thun M, Coates R, et al. Demographic and geographic variability of kidney stones in the United States. Kidney Int. 1994; 46:893-9.

7. Sánchez-Martín F, Millan Rodríguez F, Esquena Fernández S, et al. Incidence and prevalence of published studies about urolithiasis in Spain. A review. Actas Urol Esp. 2007; 31:511-20.

8. Amato M, Lusini M, Nelli F. Epidemiology of nephrolithiasis today. Urol Int. 2004; 72 (Suppl. 1):1-5.

9. Serio A, Fraioli A. Epidemiology of nephrolithiasis. Nephron. 1999; 81 (Suppl. 1):26-30.

10. Hesse A, Brändle E, Wilbert D, et al. Study on the prevalence and incidence of urolithiasis in Germany comparing the years 1979 vs. 2000. Eur Urol. 2003; 44:709-13.

11. Trinchieri A, Coppi F, Montanari E, et al. Increase in the prevalence of symptomatic upper urinary tract stones during the last ten years. Eur Urol. 2000; 37:23-5.

12. Trinchieri A. Epidemiology of urolithiasis: an update Clinical Cases in Mineral and Bone Metabolism. 2008; 5:101-106.

13. Andersen DA. Histological and geographical differences in the pattern of incidence of urinary stones in relation to possible aetiological factors. Renal stone research. Edinburgh: Churchill Livingstone 1969; 22-29.

14. Pak CY. Kidney stone. Lancet. 1998; 351:1797-1801.

15. Hesse A, Siener R. Current aspects of epidemiology and nutrition in urinary stones. World J Urol. 1997; 15:167-171.

16. Trinchieri A. Epidemiology of urolithiasis. Arch It Urol. 1996; 68:203-250.

17. Finlayson B. Renal lithiasis in review. Urologic Clinics of North America 1974; 180-1.

18. López M, Hoppe B. History, epidemiology and regional diversities of urolithiasis Pediatr Nephrol. 2010; 25:49-59.

19. Sternberg K, Greenfield SP, Williot P, Wan J. Pediatric stone disease: an evolving experience. J Urol. 2005; 174:1711-1714.

20. Scales CD Jr, Curtis LH, Norris RD, et al. Changing gender prevalence of stone disease. J Urol. 2007; 177:979-82.

21. Stamatelou KK, Francis ME, Jones CA, et al. Time trends in reported prevalence of kidney stones in the USA:1976-1994. Kidney Int. 2003; 64:1817-1823.

22. Vitale C, Tricerri A, Manganaro M, et al. Clinical and metabolic features of renal calculi in adults in regard to age of onset. Minerva Urol Nefrol. 1999; 51:71-74.

\section{Correspondence}

Domenico Prezioso, MD (Corresponding Author)

Ester Illiano, MD

Department of Neuroscience, Reproductive Sciences and Dentistry. University Federico II of Naples, Naples, Italy

Gaetano Piccinocchi, MD - SIMG. Italian Society of General Medicine Claudio Cricelli, MD - SIMG. Italian Society of General Medicine Roberto Piccinocch, MD - University "Campus Biomedico" of Rome, Italy Alberto Saita, MD - Department of Urology. "Vittorio Emanuele Hospital". University of Catania, Italy

Carla Micheli, MD - Department of Urology and Andrology. Santa Maria della Misericordia Hospital. University of Perugia, Perugia, Italy

Alberto Trinchieri, MD - Department of Urology Alessandro Manzoni Hospital of Lecco, Lecco, Italy 